\title{
Oxidative Stress in Pregnancy
}

\author{
Dr. P.Saikumar ${ }^{1}$, Dr.B.Jaya ${ }^{2}$, Dr.M.R.Renuka Devi ${ }^{3}$ \\ ${ }^{1,2,3}$ Dept of Physiology, Sree Balaji Medical College \& Hospital,Chromepet, Bharath University, India
}

\begin{abstract}
The aim of the study was to evaluate oxidative stress in uncomplicated pregnancy by determining the serum malondialdehyde (MDA) and ceruloplasmin (Cp) levels. The study was performed on 100 women attending the antenatal outpatient department of Sree Balaji Medical college and Hospital, Chromepet. Serum $M D A$ and $C p$ levels were measured in the venous blood samples taken in the first and second trimesters of pregnancy. Serum Malondialdehyde was estimated by manual method of Thiobarbituric reactive substances. Serum Ceruloplasmin level was estimated manually by Paraphenylene diamine method ${ }^{6}$. The results were compared between the first and second trimester. MDA levels were high in the second trimester compared to the first trimester (with a p value $=0.01$ ). Cp levels were high in the second trimester compared to the first trimester ( with a $p$ value $=0.01$ ). The conclusion of the research were the pregnant women in the second trimester have increased level of oxidative stress.
\end{abstract}

Keywords: pregnancy, Oxidative stress, Malondialdehyde, Ceruloplasmin

\section{Introduction}

Oxidants (reactive oxygen species) are normal products of aerobic metabolism. They are called free radicals and include superoxide radical, hydroxyl radical and hydrogen peroxide. When produced in excess, they can be harmful.

The level of the oxidants is controlled by antioxidant enzymes and small molecule antioxidants ${ }^{1,2}$. Antioxidants inhibits or delays the activity of oxidant.

Oxidative Stress occurs due to an imbalance between the reactive oxygen species and the antioxidant levels ${ }^{3,1}$. There is escape of free radicals from mitochondrial electron transport chain. These act on membrane lipoproteins \& polyunsaturated fatty acids and produce lipid peroxidation products. Malondialdehyde is a decomposition product of peroxidation of polyunsaturated fatty acid that is present in tissues and body fluids and can be measured to assess the stress.

Normal pregnancy is associated with high metabolic demand and elevated requirements for tissue oxygen. There is increased production of reactive oxygen species ${ }^{4}$. This results in increased oxidative stress.

To combat the oxidative stress, antioxidant levels may increase. Ceruloplasmin an alpha 2 globulin that transports copper can act as an antioxidant as an adaptive response to the increase in oxidant. It is an acute phase protein .

\section{Materials \& Methods}

After obtaining institutional ethical committee clearance, 100 Antenatal subjects attending Sree Balaji Medical College \& Hospital, Chromepet OBG OP with normal nutritional habits were chosen for the study. Written Informed consent were obtained, Subjects with history of abortion, recent surgery, diabetes , hypertension \& other chronic ailments were excluded from the study.

Fasting venous samples were collected from the antenatal subjects in the first trimester. Major diseases which could affect the oxidant and antioxidant levels were eliminated by doing $\mathrm{Hb}$, TC, ESR, liver function tests and serum creatinine.

Serum MDA level was estimated by manual method of TBARS $^{5}$ (Thiobarbituric acid reactive substances). The serum was treated with thioarbituric acid and heated in boiling waterbath. The concentration of MDA was measured after extracting with butanol. Serum $\mathrm{Cp}$ level was estimated manually based on the principle similar to William et al using Paraphenylene diamine dye ${ }^{6}$.

The same subjects were followed in the second trimester and serum MDA and Cp were estimated. Statistical analysis was done and the values between the trimesters were compared using paired $t$ test .

\section{Results}

Table : comparing MDA and Cp Levels between $1^{\text {st }}$ and $2^{\text {nd }}$ trimesters

\begin{tabular}{|l|l|l|l|l|}
\hline & $\mathrm{T} 1 \mathrm{n}=100$ & $\mathrm{~T} 2 \mathrm{n}=100$ & Mean difference & $\mathrm{P}$ Value \\
\hline MDA nmol/ml & $1.61 \pm 0.76$ & $2.89 \pm 0.94$ & 1.28 & $\mathrm{p}=0.01$ \\
\hline $\mathrm{Cp} \mathrm{mg} / \mathrm{dl}$ & $38.73 \pm 4.16$ & $46.25 \pm 3.96$ & 8.48 & $\mathrm{p}=0.01$ \\
\hline
\end{tabular}

T1: first trimester, T2: second trimester, MDA : Malondialdehyde , Cp: Ceruloplasmin 
Fig1:MDA levels in $1^{\text {st }}$ and $2^{\text {nd }}$ trimester

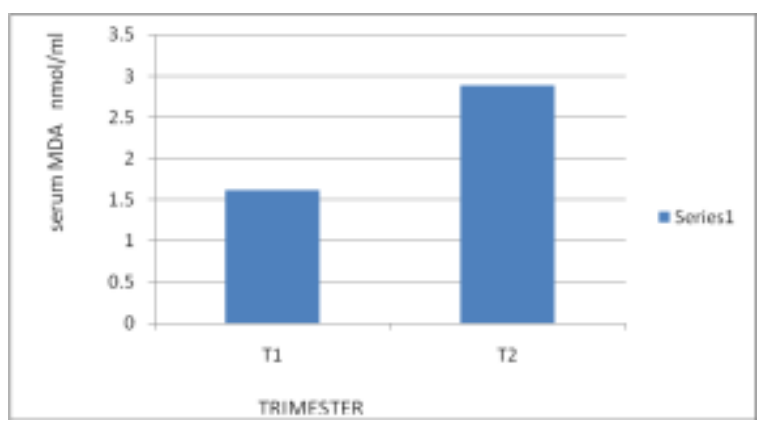

Fig $2:$ Cp levels in $1^{\text {st }}$ and $2^{\text {nd }}$ trimesters in $\mathrm{mg} / \mathrm{dl}$

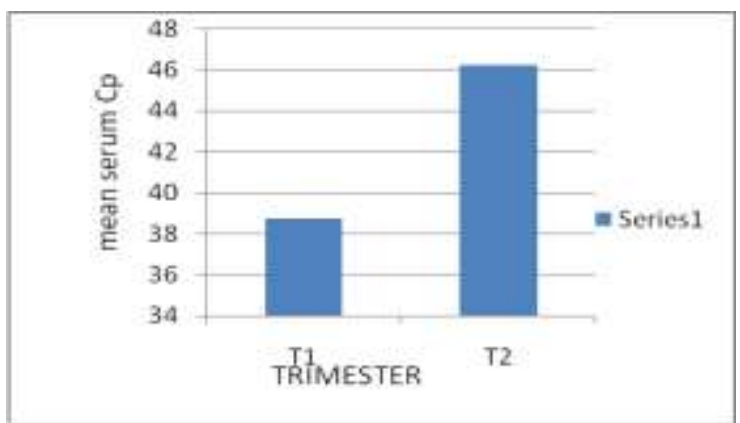

The mean serum MDA level(Fig 1) was significantly higher in the second trimester $(2.89 \mathrm{nmol} / \mathrm{ml})$ compared to the first trimester $(1.61 \mathrm{nmol} / \mathrm{ml}$ ) with a $\mathrm{p}$ value $=0.01$. The mean serum $\mathrm{Cp}$ level (fig 2)was higher in the second trimester $(46.25 \mathrm{mg} / \mathrm{dl})$ compared to the first trimester $(38.73 \mathrm{mg} / \mathrm{dl})$ with $\mathrm{p}$ value $=0.01$.

\section{Discussion}

The mean serum MDA levels in the antenatal subjects in the second trimester are significantly higher than the first trimester. Pregnancy is a physiological condition in which women are prone to oxidative stress due to imbalance between pro-oxidant and antioxidant factors ${ }^{7}$. This could be due to increased mitochondria in placenta and increased partial pressure of oxygen in pregnant women.

The mean serum $\mathrm{Cp}$ level in the antenatal subjects in the second trimester is significantly increased compared to the first trimester. Lee et $\mathrm{al}^{8}$ determined high activity of $\mathrm{Cp}$ during second half of pregnancy in rats.

Transition metals such as iron $\left(\mathrm{Fe}^{2+}\right)$ react with superoxide, hydrogen peroxide and the lipid peroxides to produce the oxygen radicals that generate oxidative damage and initiate lipid peroxidation ${ }^{9}$. Once lipid peroxidation is initiated it becomes self propagating and continues until it is interrupted by antioxidants. Ceruloplasmin has an important antioxidant effect which is paradoxically due to its ferroxidase activity. It oxidizes $\mathrm{Fe}^{2+}$ to $\mathrm{Fe}^{3+}$ and helps in the formation of $\mathrm{Fe}^{3+}$ transferrin , thus limiting the production of hydroxyl radicals and thereby can protect against oxidative cell injury ${ }^{10.11}$.

\section{Conclusion}

Uncomplicated pregnancy is associated with increased oxidative stress and lipid peroxidation as shown by the increased serum MDA levels as gestation advances. The serum ceruloplasmin levels are increased in the second trimester in comparison to the first trimester. The beneficial effect may be due to its antioxidant activity.

\section{References}

[1] Miao L, St Clair DK Regulation of Superoxide dismutase genes; implications in disease. Free Radic Biol Med.2009,Aug15,47(4),344-56

[2] Mohora Maria, Greabu Maria, Totan Alexandra, Mitrea Niculina, Battino Maurizio Redox-Sensitive Signaling factors and antioxidants.Farmacia,2009,vol57(4),399-411

[3] Sugino N,S.Takiguchi ,T.Umekawa, A.Heazell, I.Caniggia Oxidative stress and pregnancy outcome: A workshop report, Placenta 28,Supplement A, Trophoblast Research, vol 21,2007,S48eS50,

[4] Fialova L, Malhoban I, Kalousova M, Soukupova J, Krofta L Stipek S, Zima T, Oxidative stress and inflammation in pregnancy. Scand J Clin Lab Invest 66,121-127,2006

[5] Lalita Chaudary et al. Lipid peroxidation and anti-oxidant enzymes in gestational diabetics .Indian J of Physiol and Pharmacol 2003;47(4):441-446.

[6] Shaikh Shamim M., Vivian D'Souza, Poornima Manjrekar. Acute phae proteins in newly diagnosed diabetes. Biomedical Research .2008;19(1):49-53

[7] Adiga U, Adiga MNS. Total antioxidant activity in normal pregnancy. On line J Health Allied Scs.2009,8(2).

[8] Sang H Lee 1993,Robert Lancey, Anahita Montaser,Navid Madani, Maria C. Linder. Ceruloplasmin and copper transport during the latter part of gestation in the rat. Exp Biol Med.1993;203:428-439

[9] Walsh S W. Lipid peroxidation in pregnancy. Hypertensive Preg. 1994; 13:1-25.

[10] Halliwell B Gutteridge JM. The antioxidants of human extra cellular fluids. Arch Biochem Biophys.1990; 280:1-8

[11] Agroyannis B ,Kalogirou D, Vitoratos N, Tzanatos H, Koutsikos D, Zourlas P A. Serum changes of ferroxidases and iron binding capacity in pregnancy. Clin Exp Obstet Gyn. 1993; XX: 70-75 